\title{
Disinfection of Medical Devices
}

\author{
A.D. Strekalovskaya ${ }^{1, *}$, O.V. Baranova ${ }^{1}$, A.V. Rachinskih ${ }^{1}$, A.A. Bakaev ${ }^{1}$ and E.A. \\ Drozdova $^{1}$
}

${ }^{1}$ Orenburg state university, department of medical and biological equipment

*Corresponding author. Email: kwan111@yandex.ru

\begin{abstract}
The problem of waste management of medical and preventive institutions (MPI) in the Russian Federation in modern conditions is considered as an important epidemiological and environmental component of the safety of the population of the country. Since 1979, the World Health Organization has classified medical waste as hazardous and recommended the creation of special services for their recycling. The Basel Convention in 1992 identified 45 types of hazardous waste, the list of which opens with "clinical" waste. The specificity of medical waste of MPI is associated with the presence of pathogenic microflora in them in one way or another. The content of microorganisms in them is 1000 times higher than in solid household waste, the total microbial number is significantly higher in them compared to household waste, pathogenic bacteria and viruses are detected. In addition to the bacteria of the E. coli and Proteus bacillus group, pathogens of viral infections, tuberculosis and anthrax are often found in the medical waste of MPI. Potentially infected waste is characterized by high polymorphism, so a wide variety of morphological composition, which can be represented by leftovers of food and packaging materials that have been in contact with infectious patients, used dressings, personal hygiene items, dishes and instruments for sampling, syringes, needles and so on.
\end{abstract}

Keywords: disinfection, medical waste, healthcare waste, disinfection, E. coli

\section{INTRODUCTION}

Since the dawn of mankind, people have died en masse from various infectious diseases. They had no idea what caused such diseases, and did not know how to deal with it. At that time, microbes and viruses, as well as ways to protect against them, were not yet discovered. Even doctors performed operations in ordinary non-sterile clothes, and they didn't always wash their hands. As disinfection measures, certain herbs were applied to wounds, tools were calcined on fire. But the effect of cleanliness on health was guessed even then. In ancient Rome, baths were invented for this. And in writing "Domostroy" Slavs paid great attention to the cleanliness of the body and clothing.

Only after the dark times of the Middle Ages, active research in this area began from the end of the 16th century.

Today in Russia there are several regulatory documents regulating the processing of laundry in laundries:
- Methodical instructions (MI) 3.5.736-99 "Technology of treatment in medical institutions", approved by the Chief State Sanitary Doctor of the Russian Federation on 16.03.1999;

- The Sanitary Regulations and Norms (SanR and N) 2.1.3.2630-10 "Sanitary and epidemiological requirements for organizations engaged in medical activities", approved by Resolution No. 58 of 18.05.2010. Chief State Sanitary Doctor of the Russian Federation;

- "Methodological guidelines for disinfection, presterilization cleaning and sterilization of medical devices" (MI-287-113). They were approved by the Department of State Sanitary and Epidemiological Supervision of the Ministry of Health of the Russian Federation on 30.12.1998 [1].

Unfortunately, when studying these documents, it becomes obvious that most of them are outdated and do not guarantee the main thing - high-quality treatment 
and disinfection of equipment from medical institutions in modern conditions, namely:

- recommendations are given for processing equipment that is not used today;

- the specified norms of the costs of disinfectants (hydrogen peroxide) do not provide an effective disinfection regime;

approved conditions (water hardness - up to $5^{\circ} \mathrm{Dh}$, washing capacity - not less than $30 \%$ ) do not ensure the removal of contaminants, but only contribute to their fixation on the surface of the equipment.

However, in addition to improving the regulatory framework, we urgently need effective control of the processes of disinfection and treatment of the surface and internal parts of equipment, and at all stages, and before carrying out repairs or disposal of decommissioned equipment.

Today most service organizations and medical institutions in Russia don't carry out complex processing of equipment before repair, but an organization that assumes obligations to repair and dispose of medical equipment [2].

In addition, if the technology is not followed and the equipment is not properly processed, the latest resource optimization technologies can play a cruel joke. So it was revealed that in the absence of control, microorganisms accumulate on the equipment.

To prevent the risk of diseases of employees in service organizations and medical institutions, it is necessary to carry out a number of sanitary and hygienic measures. The purpose of these measures should be to reduce the risk of infection, reduce the risk of liability, increase the level of safety, strict adherence to approved production processes.

An important role in raising the standards of equipment processing is also played by the nascent domestic market for equipment rental, which could be operated in different conditions.

Both service organizations and medical institutions should work together to ensure maximum cleanliness of the equipment and its microbiological safety [3].

A modern medical organization can be considered in the context of a complex ergotechnical system, since almost everyone has sophisticated high-tech medical equipment (laboratory diagnostic and functional medical equipment).

In the national concept of prevention of infections associated with the provision of medical care, great importance is attached to the improvement of disinfection and sterilization measures in medical organizations, including in neonatology. More than 30 years have passed since the release of the orders of the
Ministry of Health of the USSR, which regulate methods and means of disinfection of couvezes, disinfection and sterilization of artificial ventilation devices. Since the 1980s. the list of disinfection products has been significantly expanded, new methods of chemical decontamination of medical products have been introduced: high-level disinfection, combination of disinfection and pre-sterilization cleaning in one stage, widespread use of ultrasonic installations to improve the quality of cleaning from biological and mechanical stress, for disinfection of medical products. Naturally, new requirements and technologies have found their application in neonatology. Modern conditions require new campaigns to carry out disinfection measures, which is reflected in the Sanitary Rules.

With the transition of Russia to the new criteria for fetal viability adopted by WHO (the weight of a premature newborn from $500 \mathrm{~g}$ ), the number of premature babies with extremely low body weight (ELBW) and very low body weight (VLBW) has sharply increased, which required the development of high technologies for their nursing, the creation of perinatal centers, equipping neonatal intensive care units (UNIC) and pathology of newborns and premature infants (UPNPI) of perinatal center to provide highly qualified specialized medical care, and in maternity hospitals - intensive care wards.

The body of even a healthy full-term newborn baby goes through a period of adaptation to extrauterine life. A premature baby has a deeply immature body that is not ready to survive this crisis, i.e. it is not ready to adapt to the conditions of extrauterine life, and needs to maintain functions. During this period, much depends on the professionalism and clarity of the actions of the medical staff.

Primary resuscitation can be provided already in the delivery room: from 5 to $6 \%$ of newborns need sanitation of the upper respiratory tract and additional oxygen supply. Therefore, the primary task is to carry out resuscitation measures to ensure the vital activity of the body. When performing the above procedures, sterile products are used, mainly single-use, medical personnel carry out procedures in aseptic conditions - a prepared room, sterile dressing gown, mask, napkins, sheets, cotton gauze products, antiseptic hand treatment and the use of single sterile gloves, glasses to protect the eyes [4].

The frequency of infections associated with the provision of medical care (IAPMC) in the Department of intensive care and intensive care reaches 230 cases per 1000 newborns. Infections are caused by opportunistic and pathogenic microflora during the stay in the Department of intensive care and intensive care. The high risk of IAPMC joining the Department of intensive care and intensive care is determined by the features of the therapeutic and diagnostic process 
associated with artificial lung ventilation (ventilator), massive infusion therapy, vascular explants.

Risk factors for newborns are:

- multiple organ failure;

- immunodeficiency;

- extremely low body weight;

- respiratory distress syndrome.

One of the problems of operation and disposal of medical equipment in institutions engaged in the diagnosis and treatment of infectious diseases is contamination not only of the external surfaces, but also of the internal components of the devices by pathogenic microorganisms and viruses. During the repair and disposal of this equipment, it is possible that the personnel servicing this equipment may become infected. As is known, microorganisms have a high level of resistance in the external environment, but the impact of various physico-chemical factors on them can have a pronounced bactericidal effect.

At the same time, it is worth noting that the internal components of medical equipment are expensive and cannot be subjected to aggressive disinfection methods, which in turn makes the use of chemical solutions and a reagent for disinfection unacceptable [5].

At the same time, in addition to chemical effects on medical devices, you can also choose physical methods of cleaning. According to SanR and N 2.1.3.2630-10 "Sanitary and epidemiological requirements for organizations engaged in medical activities" (hereinafter - SanR and N 2.1.3.2630-10) to reduce air contamination to a safe level in medical organizations, technologies for exposure to ultraviolet radiation, aerosols of disinfectants, and in some cases ozone, bacterial filters are used.

(UV) bactericidal irradiation of indoor air is a traditional and most common sanitary and anti-epidemic (preventive) measure aimed at reducing the number of microorganisms in the air of medical organizations and preventing infectious diseases.

UV rays are part of the spectrum of electromagnetic waves in the optical range. They have a damaging effect on the DNA of microorganisms, which leads to the death of the microbial cell in the first or subsequent generations. The spectral composition of UV radiation causing bactericidal action lies in the wavelength range of 205-315 nm.

Viruses and bacteria in vegetative form are more sensitive to UV radiation than mold and yeast fungi, spore forms of bacteria.

The effectiveness of bactericidal disinfection using $\mathrm{UV}$ radiation depends on:
- the species of microorganisms in the air;

- spectral composition of UV radiation;

- the intensity of the pulse emitted by the source of $\mathrm{UV}$ rays;

- distance from the source, angle of incidence of UV rays.

Discharge lamps are used as sources of UV radiation. The physical basis of their functioning is an electric discharge in metal vapors, in which radiation with a wavelength range of $205-315 \mathrm{~nm}$ is generated in these lamps (the rest of the radiation spectrum plays a secondary role).

Low-pressure mercury lamps structurally and in electrical parameters practically do not differ from conventional fluorescent lighting lamps, except that their bulb is made of special quartz or UV glass with a high transmittance of UV radiation, its inner surface is not coated with a layer of phosphor [6].

However, these lamps have a low bactericidal output and a short service life (500-1000 hours). In recent years, a new generation of emitters has appeared xenon short-pulse lamps. The advantage of xenon flash lamps is due to higher bactericidal activity and shorter exposure time. The advantage of xenon lamps is also that if they are accidentally destroyed, the environment is not polluted by mercury vapor.

A bactericidal irradiator is an electrical device that includes: a bactericidal lamp, a reflector and other auxiliary elements, as well as attachment devices. Bactericidal irradiators redistribute the flow of radiation generated by the lamp into the surrounding space in a given direction. All bactericidal irradiators are divided into two groups - open and closed (fig 1-2).

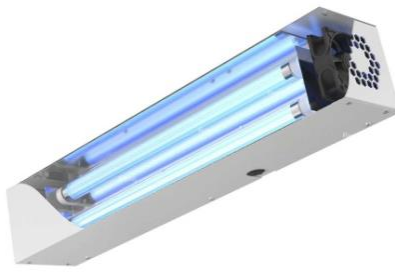

Figure 1. Bactericidal irradiator of the open type

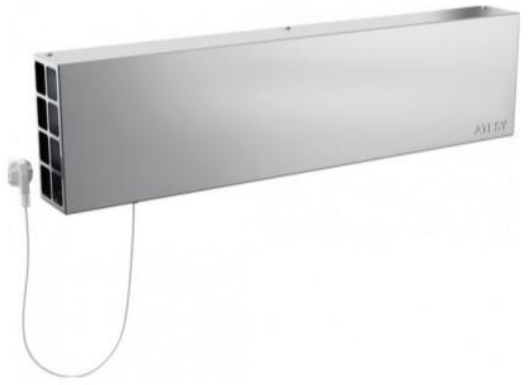

Figure 2. Bactericidal irradiator of the closed type 
In open irradiators, a direct bactericidal flow from lamps and a reflector (or without it) is used, which covers a certain space around them. Such irradiators are installed on the ceiling, wall or in doorways, mobile (mobile) versions of irradiators are possible.

A special place is occupied by open combined irradiators. In these irradiators, due to the rotary screen, the bactericidal flow from the lamps can be directed both to the upper and lower zones of the space. However, the efficiency of such devices is significantly lower due to the change in wavelength during reflection. When using combined irradiators, the bactericidal flow from shielded lamps should be directed to the upper zone of the room in such a way as to exclude the direct flow from the lamp or reflector to the lower zone.

When using bactericidal lamps in the supply and exhaust ventilation, they are placed in the output chamber. Indoors, it is preferable to install irradiators near ventilation ducts.

This air and surface treatment technology is recommended as the main/auxiliary or alternative method for disinfection of air and surfaces during the final disinfection [7].

Ozone is a chemical substance whose molecule consists of three oxygen atoms. The ozone molecule is unstable. When interacting with other substances, ozone easily loses oxygen atoms and therefore ozone is one of the most powerful oxidizers, far surpassing diatomic oxygen air (second only to fluorine and unstable radicals). It oxidizes almost all elements, with the exception of gold and platinum.

Ozone vigorously enters into chemical reactions with many organic compounds. This explains its pronounced bactericidal effect. Ozone reacts actively with all cell structures, more often causing a violation of permeability or destruction of the cell membrane. Ozone also has a deodorizing effect.

Ozone therapy can be used in the treatment of COVID19 in two therapeutic categories:

1) Disinfection (considered to have high evidence):

a) Contaminated environment (hospitals, transport, vehicles, all surfaces where the virus could be deposited, etc.);

b) In aqueous solutions such as disinfection of drinking water, wastewater treatment, laundries and food processing.

2) Potential systemic use as an additional drug in order to:

a) improve the health of patients and reduce viral load [8];

b) In the form of ozonated mouthwash water to reduce the incidence of ventilator-associated pneumonia in patients associated with artificial lung ventilation. Ozone must be produced using a medical, reliable and certified generator. Ozone generators are medical devices classified in the European Union as medical devices of Class IIb, and they have the $\mathrm{CE}$ marking accompanied by four numbers (Article 9, Council Directive 93/42/EEC, in accordance with Annex IX of the same Directive). The generator should be able to measure accurate ozone concentrations (from $1 \mathrm{mg} / \mathrm{l}-80 \mathrm{mg} / \mathrm{ml}$ ) and produce ozone exclusively from medical oxygen coming from a container certified for medical quality. The equipment should be able to regulate the output flow between $200-500 \mathrm{ml} / \mathrm{min}$ and be able to control continuous flow at very low concentrations (2-5 micrograms $/ \mathrm{ml}$ ). Disposable materials for therapy should be free of phthalates and resistant to ozone. They must have the same classification as the ozone generator, Class IIb (medical device). Ozone can be useful for disinfection, its maximum antiviral effectiveness requires a short period of high humidity (> $90 \%$ relative humidity) after reaching the peak concentration of gaseous ozone (20-25 ppm, $\left.39-49 \mathrm{mg} / \mathrm{m}^{3}\right)$. In any case, the places should be free of people due to the toxicity of ozone when inhaled. People and animals should not be in the treated environment due to the relative toxicity of ozone when inhaled. Systemic ozone therapy may be potentially useful in SARS-CoV-2 [8]. The rationale and mechanism of action have already been clinically proven for other viral infections and have shown high efficacy in scientific research. The mechanism of action is as follows:

1) Induction of adaptation to oxidative stress and, consequently, restoration of the equilibrium of the redox state of cells.

2) Induction of IFN-gamma and anti-inflammatory cytokines.

3) Increased blood flow and oxygenation of tissues of vital organs (i.e. renal, pulmonary and cardiac circulation).

4) It can act as an autovaccine when administered in the form of minor autohemotherapy.

Ozone in terms of toxicity parameters belongs to hazard class I (according to GN.2.2.5.1313-03). The average daily maximum permissible concentration of the maximum permissible concentration of ozone in the atmospheric air is $0.03 \mathrm{mg} / \mathrm{MZ}$; the maximum permissible concentration of ozone in the air of the working area is $0.1 \mathrm{mg} / \mathrm{MZ}$. When using an ozonizer for disinfection, the concentration of ozone in the air of a room or chamber can reach $5-10 \mathrm{mg} / \mathrm{moH}$ or more. The estimated concentration of ozone (the amount of ozone produced in 1 hour divided by the volume of the room) is $20-100 \mathrm{mg} / \mathrm{moH}$. The difference between the actual values of ozone concentrations and the calculated values is explained by the significant consumption of ozone for chemical transformations and adsorption by its surfaces. The adsorption of ozone by surfaces blocks them from microorganisms and causes a prolonged disinfection effect. 
The ozonator in the maximum performance mode, depending on the design, generates ozone from air oxygen from 5 to $120 \mathrm{~g} / \mathrm{h}$. Ozone has a pronounced antimicrobial effect on the entire spectrum of pathogenic microflora and is a universal, environmentally friendly, effective and the cheapest disinfectant. It is known that substances of organic nature (products of the vital activity of the organism and man-made activity) are present in the indoor air; in comparison with atmospheric air, the indoor air is very polluted. Ozonation helps to clean the indoor air environment; as a result of ozonation, the concentration of toxic substances and pathogenic microflora decreases, odors are eliminated, people's well-being improves, and morbidity decreases. Ozone itself decays quickly enough at room temperature, turning into oxygen, the half-life of ozone at room temperature is about 20 minutes.

To select the power of the ozonator, it is necessary to proceed from the volume of the room and the required operating mode

For deodorization and disinfection, the required concentration of ozone is $1 \mathrm{~g}$ per $35 \mathrm{~m}^{3} / \mathrm{h}$. To remove mold, the required concentration of ozone is $1 \mathrm{~g}$ per $15 \mathrm{~m}^{3} / \mathrm{h}$. For the deratization of rodents and insects, the required concentration of ozone is $1 \mathrm{~g}$ per $15 \mathrm{~m}^{3} / \mathrm{h}$. For example: it is necessary to process a room with a volume of $350 \mathrm{~m}^{3}$. For disinfection, the required concentration is $1 \mathrm{~g}$ per $35 \mathrm{~m}^{3}$, we get an ozonator with a capacity of $10 \mathrm{~g} / \mathrm{hour}$. To remove mold in this room, an ozonator with a capacity of $20 \mathrm{gr} /$ hour is required. An example of an ozonator is shown in Figure 3.

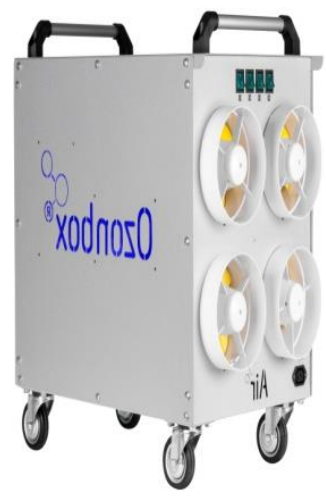

Figure 3. Ozonator

\section{CONCLUSION}

Thus, it is proposed to develop a portable installation with a combination of bactericidal treatment of the surface of products with ozonation of the internal surfaces of products.

\section{REFERENCES}

[1] J. Pépin, C.N. Abou Chakra, E. Pépin et al., Evolution of the global burden of viral infections from unsafe medical injections, 2000-2010, PLoS One 9(6) (2014) e99677.

[2] B. Haas, K.J. Soto, D.S. Day et al., Mycobacterium hassiacum: A thermophilic Mycobacterium species to demonstrate thermal disinfection of medical devices, BMC Res. Notes 13(1) (2020). Retrieved from: https://doi.org/10.1186/s13104-020-04978-7

[3] K.R.S. Allou, J. El Harti, Mapping risk management in pre-disinfection of medical devices in a hospital environment. The example of the central sterilization laboratory of the Ibn Sina Hospital, Rabat, Morocco, Pharmac. Hospit. et Clin. 53(4) (2018) 279-287. Retrieved from: https://doi.org/10.1016/j.phclin.2018.05.004

[4] R.E. Harrington, T. Guda, B. Lambert, J. Martin, Sterilization and Disinfection of Biomaterials for Medical Devices, Biomat. Sci. (2020) 1431-1446. Elsevier. DOI: ORG/10.1016/B978-0-12-8161371.00091-X

[5] M. Moisan, K. Boudam, D. Carignan et al., Sterilization/disinfection of medical devices using plasma: The flowing afterglow of the reducedpressure N2-O2 discharge as the inactivating medium, EPJ Appl. Phys. 63(1) (2013) 46. Retrieved from: https://doi.org/10.1051/epjap/2013120510

[6] J.A. Byrne, P.S.M. Dunlop, J.W.J. Hamilton et al., A review of heterogeneous photocatalysis for water and surface disinfection, Molec. 20(4) (2015) 5574-5615. Retrieved from: https://doi.org/10.3390/molecules20045574

[7] B.C. Millar, J. Stirling, M. Maguire et al., Repurposing of domestic steam disinfectors within the hospital-at-home setting, Infect., Dis. and Health 26(1) (2021) 72-80. Retrieved from: https://doi.org/10.1016/j.idh.2020.09.005

[8] C. Ackert-Burr, Best practices for sterilization and High-Level Disinfection of reusable medical devices, J. of Microbiol., Immunol. and Infect. 48(2) (2015) S10-S11. Retrieved from: https://doi.org/10.1016/j.jmii.2015.02.134 